\title{
CELLULAR CONVECTION OVER THE NORTH-EASTERN ATLANTIC
}

\author{
S. BAKAN \\ Max-Planck-Institut für Meteorologie, Germany \\ AND \\ E. SCHWARZ \\ Meteorologisches Institut der Universität Hamburg, Germany \\ Received 25 April 1991 \\ Accepted 31 December 1991
}

\begin{abstract}
Convective clouds over the ocean frequently exhibit organized meso-scale patterns. A statistical evaluation of 4 years of NOAA satellite images over the north-eastern Atlantic yields climatological data of the appearance of these patterns and shows that open cellular convection is most abundant. For this convection type, surface and radiosonde data from Weathership $M$ have been analysed. Open convection cells appear at a wide range of positive sea-air temperature differences up to $12^{\circ} \mathrm{C}$ and at wind speeds up to $25 \mathrm{~m} \mathrm{~s}^{-1}$. All diameters have been found to be less than $80 \mathrm{~km}$ (average $41 \mathrm{~km}$ ). Larger diameters are, on average, associated with slightly larger convection heights and, thus, with larger aspect ratios.

The scene-averaged brightness temperature of AVHRR channel 4 exhibits a definite correlation with the sea-air temperature difference and, less well expressed, with the sensible and latent heat flux. This, in turn, provides a possibility of estimating those quantities by using easily accessible AVHRR satellite data.
\end{abstract}

KEYwordS Convective clouds Meso-scale convection North-eastern Atlantic

\section{INTRODUCTION}

Satellite images over the oceans frequently show organized meso-scale patterns of cumulus convection. Most prominent in middle and northern latitudes are open convection cells, in which a ring-like cloudy wall of 30-50 km diameter surrounds the virtually cloud free centre (Krueger and Fritz, 1961; Agee, 1987). Their occurrence is associated with considerable sea-air temperature differences of several degrees. Busack et al. (1985) found that the area around Weathership $M$ in the north-eastern Atlantic is covered with open cells for roughly 20 per cent of the time. Preceding these convection cells in the upstream direction, banded structures parallel to the mean wind are often observed near the coast line or ice boundary. The horizontal spacing and the vertical extent of the cloud bands has been observed to increase with the distance from the coast (e.g. Miura, 1986).

While open cells occur mostly in cold air outbreaks of the middle latitudes, vast regions of the subtropics are covered by closed convection cells (Agee et al., 1973; Agee, 1984). These appear as large cloudy patches surrounded by ring-like, cloud-free subsidence regions of about $50 \mathrm{~km}$ diameter. The atmospheric structure in these cases is characterized by a stratocumulus-topped boundary layer of about $1-2 \mathrm{~km}$ depth, which is separated clearly from the atmosphere above by a well-expressed inversion. This type of convection appears also in middle latitudes, when long-lasting high-pressure situations in summer lead to similar cloud-capped boundary layers (Brümmer and Busack, 1990). Occasionally, closed cells also have been observed as part of the development of open cells (Agee and Lomax, 1978).

0899-8418/92/040353-15\$07.50

(C) 1992 by John Wiley \& Sons, Ltd. 
Four years of NOAA satellite images over the north-east Atlantic have been surveyed for the appearance of these convection types. The data sources and the derived climatology of meso-scale cellular convection is presented in section 2. Section 3 discusses surface data collected at Weathership $M\left(66^{\circ} \mathrm{N}, 2^{\circ} \mathrm{E}\right)$ as well as the atmospheric structure encountered during open cellular convection. The possible derivation of certain characteristics of the near-surface flow from satellite data is presented in section 4 .

\section{CLIMATOLOGY OF MESO-SCALE CELLULAR CONVECTION}

\subsection{Satellite data}

The images of the routine Earth observation satellites of the TIROS N/NOAA series are especially suitable for climatological studies owing to their sun synchronous orbit, spatial and temporal coverage, and their availability since 1978. For the present study AVHRR (Advanced Very High Resolution Radiometer) data between 1 January 1980 and 31 December 1983, as received and archived at the University of Dundee, have been used. The climatological information is derived from inspection of the photographic reproductions of the original AVHRR data (channels 2-VIS and 4-IR) of the satellite overpass nearest to Dundee, which are available there in a browse file. Figure 1 shows a typical NOAA/AVHRR channel 4 scene of a cold air outbreak from Greenland. As the satellite track shifts somewhat from day to day the area of overlap of all images received in Dundee is indicated.

These images were inspected for the appearance of open and closed cells, as well as of banded cloud structures over the ocean. Connected areas of rather similar and homogeneous appearance of the convection were counted as separate cases. Therefore, one image could lead to several data sets (=cases) for later reference. For the example image (Figure 1) two cases of cloud bands near the ice boundaries in the Greenland and the Barents Sea were archived as well as four cases of open cells characterizing the north-eastern Atlantic and the northern Barents Sea. With help of a grid overlay the position of the centre of the defined area, its size, and the cell diameter (or distance between cloud bands) were estimated. The minimum distance detectable in these browse-file images was about $10 \mathrm{~km}$. Also the degree of cellular organization was crudely, and necessarily subjectively, estimated.

On only 111 days out of 4 years the satellite image did not dispay convective phenomena over the ocean. As has been mentioned by Van Delden (1985) meso-scale open cellular convection is sometimes (10 per cent of all days) also observed over land in western Europe, where it is usually less well expressed as over sea.

\subsection{Open cells}

By far most of the observed convection cases are of the open cell type. On average, 583 cases have been registered per year, so that usually more than one convection area was identified on the image. It should be mentioned that some of these cases represent convection in the same cold air outbreak but observed on consecutive days.

Figure 2 displays the monthly observed frequency of open cellular convection cases. The annual cycle is clearly defined with a maximum of cases in the winter time. The majority of cases is observed between $55^{\circ} \mathrm{N}$ and $75^{\circ} \mathrm{N}$.

The average diameter of all open-cell cases is $41 \mathrm{~km}$, with a standard deviation of $15 \mathrm{~km}$. Figure 3 shows the frequency of occurrence of several cell diameter classes, which depends considerably on the observed latitude. While north of $70^{\circ} \mathrm{N}$, cases with diameters of $20-30 \mathrm{~km}$ prevail, diameters of $50-60 \mathrm{~km}$ are most abundant south of $60^{\circ} \mathrm{N}$. However, no smooth transition from one of the two peak diameters to the other can be observed. The drop-off of all frequencies towards small diameters may be artificial owing to the previously mentioned limit of resolution of about $10 \mathrm{~km}$.

The frequency distribution of the total area of observed cell cases has its maximum at an area of around $1-2 \times 10^{5} \mathrm{~km}^{2}$. The average area size of $3.4 \times 10^{5} \mathrm{~km}^{2}$, however, indicates the frequent existence of rather large areas. Together with the observed frequency of open cellular cases an average coverage of the north-east Atlantic of 9 per cent (13 per cent in wintertime) is found with this convection pattern. 


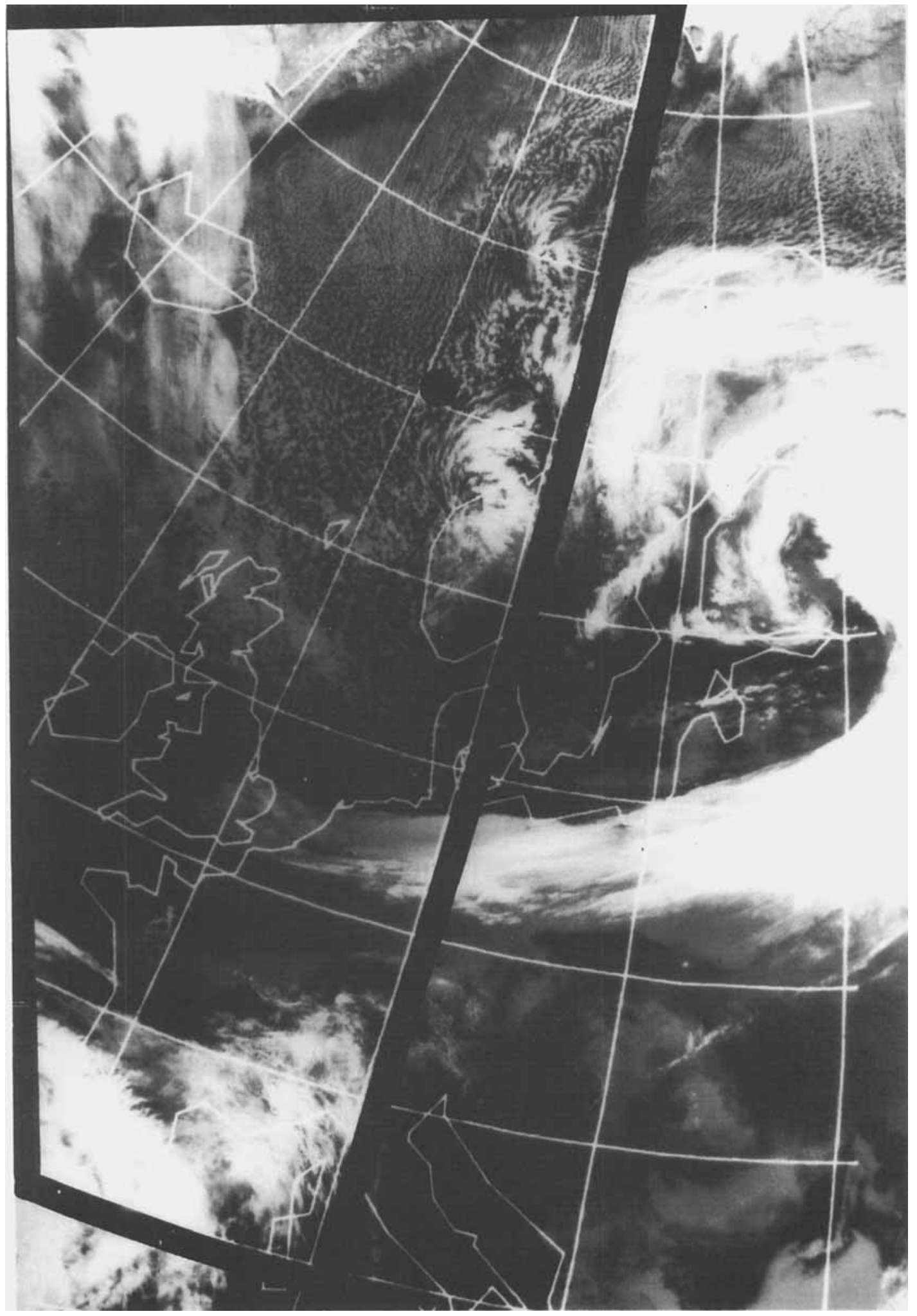

Figure 1. Typical cold air outbreak over the north-eastern Atlantic leading to the development of vast areas of open cells. NOAA7/AVHRR, channel 4 image of 23 November 1983, 13.47 UT as recorded at the University of Dundee. The area within the black boundaries indicates the region observable on any nearest-to-Dundee satellite pass. The position of weathership $\mathrm{M}\left(66^{\circ} \mathrm{N}, 2^{\circ} \mathrm{E}\right)$ is indicated 


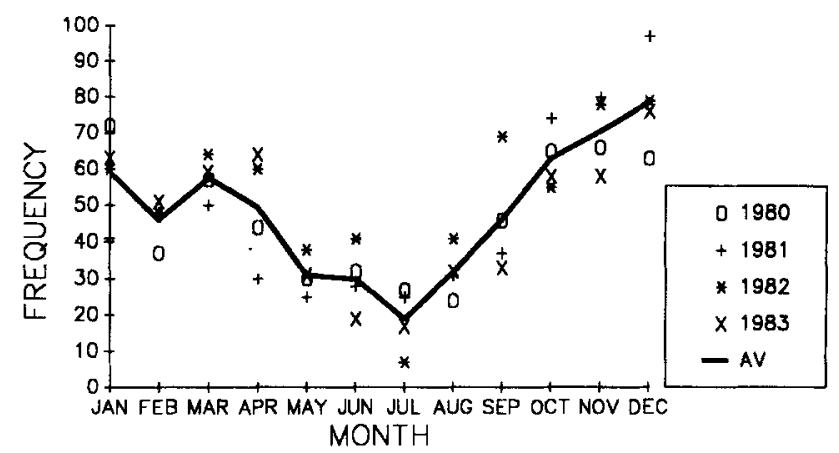

Figure 2. Monthly frequency of open cells for the period 1980-1983. The solid line represents the average value

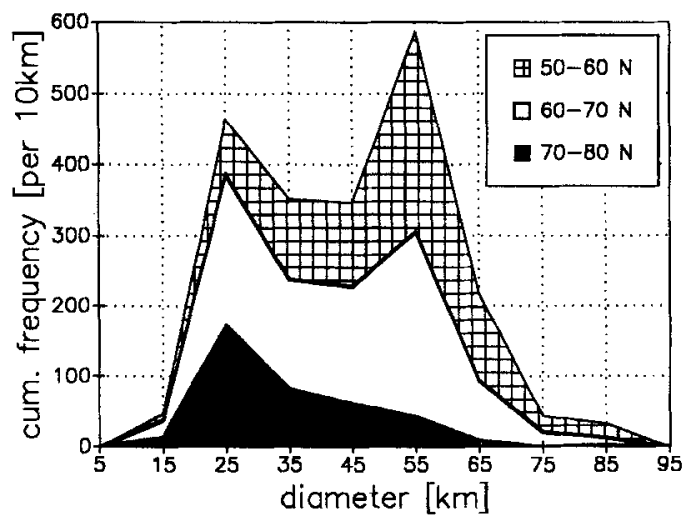

Figure 3. Cumulative number distribution of open cell cases in the period 1980-1983 versus their diameter (class width $\pm 5 \mathrm{~km}$ around the indicated value) for different latitude bands

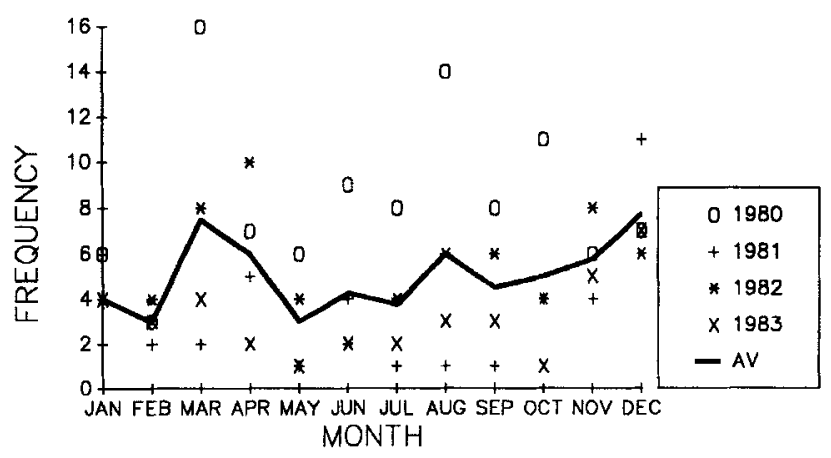

Figure 4. As in Figure 2, but for closed cells

\subsection{Closed cells}

Closed cellular situations were observed about 10 times less frequently than open cells. A considerable yearto-year variation of the monthly frequency of cases is displayed in Figure 4 and no significant yearly cycle is found. Closed-cell situations are found further to the south, mainly between $45^{\circ} \mathrm{N}$ and $65^{\circ} \mathrm{N}$. The mean 


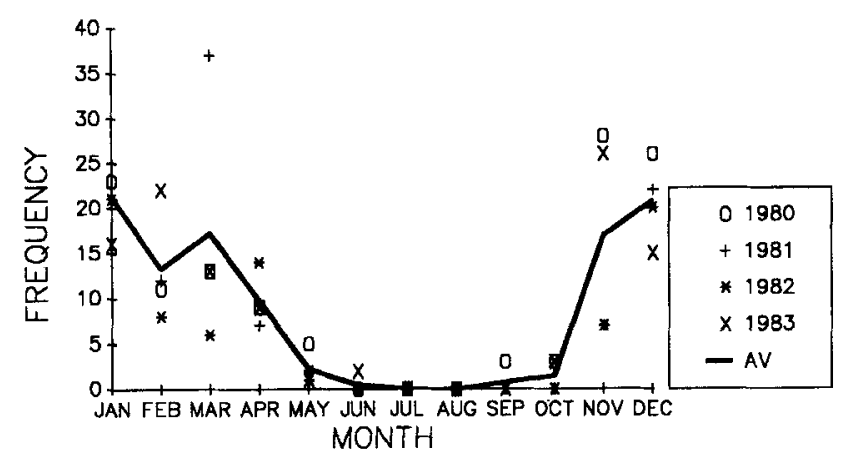

Figure 5. As in Figure 2, but for banded structures

diameter was estimated to $53( \pm 17) \mathrm{km}$, which is definitely larger than that of open cells. On the other hand the average observed size of closed cell areas of $2.6 \times 10^{5} \mathrm{~km}^{2}$ is similar to that of open cells.

\subsection{Banded structures}

Although banded structures are near the limit of image resolution a considerable number of cases was found, half of which appear in cold air outbreaks near the coast or ice boundary changing over to open cells downstream. They exhibit a very prominent yearly cycle, almost without any cases being found during the summer months (Figure 5). They are found predominantly far to the north between $70^{\circ} \mathrm{N}$ and $80^{\circ} \mathrm{N}$.

The derived average distance between the cloud bands of $14 \mathrm{~km}$ is somewhat doubtful owing to the previously mentioned lower limit of resolution of $10 \mathrm{~km}$. The mean area size is found to be about $2 \times 10^{5} \mathrm{~km}^{2}$.

\section{SURFACE DATA AND ATMOSPHERIC STRUCTURE DURING OPEN CELLULAR CONVECTION}

\subsection{Data material}

From Weathership $\mathrm{M}\left(66^{\circ} \mathrm{N}, 2^{\circ} \mathrm{E}\right)$ regular surface observations in a 3-h sequence and radiosonde observations every $12 \mathrm{~h}$ are available. For the present purpose the surface data observed at 1500 and the radiosounding of 1200 have been used, as these times are nearest to the daily satellite passes analysed. Owing to the small number of other organized convection types observed around Weathership $\mathrm{M}$, only open cellular convection is discussed in the following. The observed surface wind speed $|v|$, sea-air temperature difference, $\Delta T$, and relative humidity are used to estimate the sensible and latent heat fluxes from the bulk equations $H=\rho C_{\mathrm{D}}|v| \Delta T$ and $L E=\rho L C_{\mathrm{D}}|v| \Delta q$ ( $\rho=$ air density, $\Delta q=$ sea-air specific humidity difference). According to Hasse and Dobson (1986), a constant heat transfer coefficient $C_{\mathrm{D}} \approx 1 \cdot 3 \times 10^{-3}$ was used, which lies well within the range of values cited in literature for heat and moisture transfer coefficients in unstable conditions (e.g. Isemer and Hasse, 1987; Smith, 1988).

After examination of the available radiosoundings, 100 cases of well-organized, and 241 cases of less wellorganized, open cellular convection remained for further analysis. This means that, on average, on roughly a quarter of all days open cellular convection may be observed near Weathership M. As mentioned already by Krueger and Fritz (1961) the typical vertical profile in such a case consists of a slightly unstable layer below could base and a somewhat more stable cloud layer that is capped by a rather stable layer above. The inversion height differs considerably among the cases and is sometimes difficult to define owing to a gradual transition. Finally, we decided to take the cloud-top height as a measure of the convection height. This cloudtop height was then estimated by inspection of the profiles as the height of the lowest inversion associated with a considerable drop in relative humidity. 


\subsection{Wind speed and sea-air temperature difference}

It is assumed generally that cellular convection should be observed at large sea-air temperature differences but moderate wind speeds. Figure 6 shows that a wide range of combinations of these parameters may be found at Weathership M. Sea-air temperature differences between slightly negative values and $11^{\circ} \mathrm{C}$ as well as wind speeds between 2 and $30 \mathrm{~m} \mathrm{~s}^{-1}$ appear. These values correspond to sensible surface heat fluxes up to $300 \mathrm{~W} \mathrm{~m}^{-2}$. A general tendency towards larger sea-air temperature differences in cases with larger wind speed is observed. The wide spread of data is in some contrast to observations by Sheu and Agee (1977) in the Chinese Sea. They reported a minimum difference between sea-surface and air temperature of $5^{\circ}$ and a surface wind speed of more than $5 \mathrm{~ms}^{-1}$ as a necessary condition for the occurrence of meso-scale cellular convection. These values are not supported by the present study, but our data indicate that organized cellular convection over the open ocean may, less frequently though, be even observed with small wind speed and sea-air temperature differences.

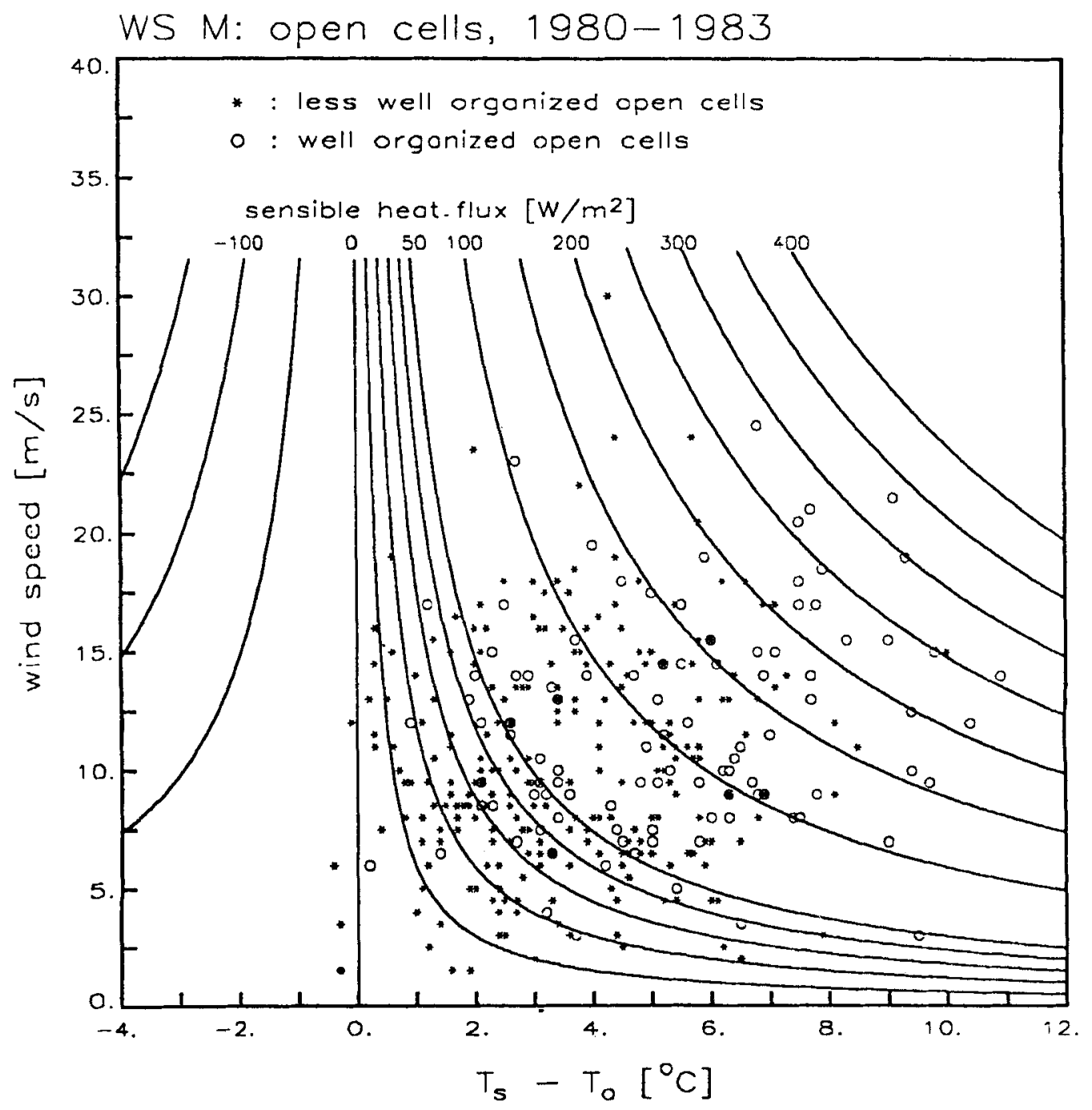

Figure 6. Wind speed versus sea-air temperature difference for the well- $(O)$ and the less well-organized (*) open cellular convection cases observed at Weathership $M$ between 1980 and 1983. The isolines of the corresponding (bulk) sensible heat flux are also plotted 


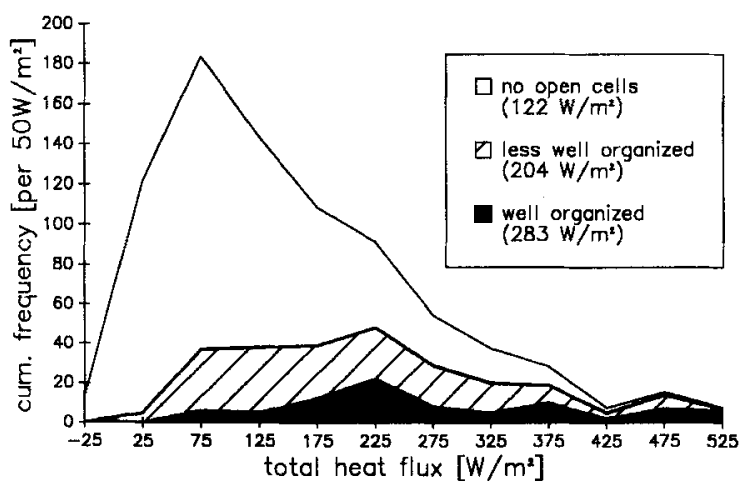

Figure 7. Cumulative frequency distribution of total (bulk) heat flux at Weathership $M$ for the winter months (October through to April) of the years $1980-1983$ for various degrees of convective organization

Figure 6 shows the tendency of well-organized cases to be associated with higher sea-air temperature differences $\left(\overline{\Delta T}=5 \cdot 3^{\circ} \mathrm{C}, \mathrm{SD}=2 \cdot 4^{\circ} \mathrm{C}\right)$ than the cases less well expressed $\left(\overline{\Delta T}=3.6 \pm 1 \cdot 9^{\circ} \mathrm{C}\right)$. Owing to the large number of observations this difference is highly significant despite the large data scatter. Even the rather small difference in the average wind speed $\left(v=11.8 \pm 4.5 \mathrm{~m} \mathrm{~s}^{-1}\right.$ for well-organized cases, $10.4 \pm 4.7 \mathrm{~m} \mathrm{~s}^{-1}$ for less well-organized cases) supports the assumption of significantly different average values $(p<0.01)$. These differences result in higher average surface heat fluxes in cases of well-organized cellular convection. Figure 7 shows the frequency distribution of total surface heat flux for well- and less well-expressed convection cell cases and for cases without organized convective activity. All three types of data appear with a wide range of surface heat fluxes. A standard $\chi^{2}$ test proves that the distributions are significantly $(p<0 \cdot 01)$ different from each other. The corresponding average flux values are least for non-convective cases $\left(122 \mathrm{~W} \mathrm{~m}^{-2}\right)$ and largest for well-expressed convection $\left(283 \mathrm{~W} \mathrm{~m}^{-2}\right)$, while cases with less well-expressed organization correspond to intermediate heat flux values $\left(204 \mathrm{~W} \mathrm{~m}^{-2}\right)$. These differences are again significant at the 99 per cent level. It seems remarkable that only for heat fluxes larger than $400 \mathrm{~W} \mathrm{~m}^{-2}$ is cellular convection observed most of the time. Below this value, a considerable fraction of cases does not exhibit cellular organization in the satellite images.

Weighting the average total heat flux for the different convection types with their observed frequency (cf. section 2) indicates that about 20 per cent of the heat input from the ocean to the atmosphere during winter time is accomplished in cases of open cellular convection.

\subsection{Cell size}

Figure 2 showed a wide range of observed cell diameters for which average surface-data values are summarized in Table I together with a measure for the significance of the variations between the diameter classes. Although the standard deviations in the different diameter classes do not differ too much, the 99 per cent confidence intervals of the class-mean values given in Table I differ by a factor of two, owing mainly to the different class population. The significance of the differences of the class mean values is characterized by the quantity (where $x$ stands for any of the tabulated variables)

$$
t_{\max -\min }=\frac{\left|x_{\max }-x_{\min }\right|}{\sigma_{\Delta}}\left(\frac{N_{\max } N_{\min }}{N_{\max }+N_{\min }}\right)^{1 / 2} \quad \sigma_{\Delta}^{2}=\frac{\left(N_{\max }-1\right) \sigma_{\max }^{2}+\left(N_{\min }-1\right) \sigma_{\min }^{2}}{\left(N_{\max }+N_{\min }-2\right)}
$$

which is calculated from the maximum and minimum values of each row. It should conform to a student's $t$-test, which indicates 99 per cent significance for values $>2.7$ (Taubenheim, 1969). The most significant variation of the observed quantities is that of the sea-air temperature difference, which shows a maximum value at intermediate cell diameters between $30 \mathrm{~km}$ and $50 \mathrm{~km}$. For the most abundant cell diameters in 
Table 1. Means \pm 99 per cent significance limits of various parameters for different cell diameter $(D)$ classes of 261 cases of open cellular convection observed near Weathership M during winter months 1980 through to 1983 . The last column gives a significance measure for the maximum - minimum variation of the mean value.

\begin{tabular}{|c|c|c|c|c|c|c|}
\hline & $D<30$ & $30 \leqslant D<40$ & $40 \leqslant D<50$ & $50 \leqslant D<60$ & $60 \leqslant D$ & $t_{\max -\min }$ \\
\hline cases & 41 & 39 & 54 & 98 & 29 & \\
\hline$f f\left(\mathrm{~ms}^{-1}\right)$ & $13 \cdot 3 \pm 2 \cdot 2$ & $11.8 \pm 1.8$ & $12 \cdot 7 \pm 1 \cdot 7$ & $10 \cdot 5 \pm 1 \cdot 3$ & $9 \cdot 7 \pm 2 \cdot 1$ & $3 \cdot 1$ \\
\hline$T_{w}\left({ }^{\circ} \mathrm{C}\right)$ & $7.2 \pm 0.6$ & $6.7 \pm 0.5$ & $6.8 \pm 0.4$ & $6 \cdot 4 \pm 0.3$ & $6.7 \pm 0.5$ & $4 \cdot 0$ \\
\hline$F_{a}^{n}\left({ }^{\circ} \mathrm{C}\right)$ & $3 \cdot 3 \pm 1 \cdot 1$ & $1 \cdot 3 \pm 1 \cdot 1$ & $1 \cdot 2 \pm 1 \cdot 0$ & $1.8 \pm 0.6$ & $3.6 \pm 1.0$ & $4 \cdot 0$ \\
\hline$\Delta T(\mathrm{C})$ & $3.9 \pm 0.9$ & $5.4 \pm 0.8$ & $5.5 \pm 0.8$ & $4.7 \pm 0.5$ & $3 \cdot 1 \pm 0.9$ & 5.0 \\
\hline$T_{\mathrm{d}}\left({ }^{i} \mathrm{C}\right)$ & $-0.9 \pm 1.6$ & $-3.8 \pm 1.6$ & $-2 \cdot 9 \pm 1 \cdot 2$ & $-2.9 \pm 0.7$ & $-1 \cdot 1 \pm 1 \cdot 2$ & $3 \cdot 5$ \\
\hline $\mathrm{RH}(\%)$ & $75 \cdot 0 \pm 5 \cdot 6$ & $69 \cdot 6 \pm 4 \cdot 5$ & $74 \cdot 4 \pm 3 \cdot 1$ & $71.9 \pm 2.9$ & $71 \cdot 8 \pm 3.7$ & $2 \cdot 1$ \\
\hline$e(\mathrm{hPa})$ & $5.9 \pm 0.7$ & $4.8 \pm 0.6$ & $5 \cdot 1 \pm 0.5$ & $5 \cdot 0 \pm 0.3$ & $5.7 \pm 0.5$ & $3 \cdot 1$ \\
\hline $\operatorname{SHF}\left(\mathrm{W} \mathrm{m}^{-2}\right)$ & $91 \cdot 3 \pm 29 \cdot 4$ & $111 \cdot 7 \pm 26 \cdot 5$ & $118 \cdot 6 \pm 26 \cdot 1$ & $82.6 \pm 13.8$ & $45 \cdot 2 \pm 14 \cdot 7$ & $5 \cdot 2$ \\
\hline $\operatorname{LHF}\left(\mathrm{W} \mathrm{m}^{-2}\right)$ & $150 \cdot 3 \pm 32 \cdot 9$ & $156 \cdot 9 \pm 30 \cdot 3$ & $156.9 \pm 24.6$ & $124.0 \pm 16 \cdot 2$ & $101 \cdot 2 \pm 25 \cdot 7$ & $3 \cdot 9$ \\
\hline $\mathrm{THF}\left(\mathrm{W} \mathrm{m}^{-2}\right)$ & $241 \cdot 5 \pm 59 \cdot 7$ & $268.6 \pm 55.7$ & $275 \cdot 6 \pm 48 \cdot 7$ & $206 \cdot 6 \pm 28.7$ & $146.5 \pm 37.4$ & $4 \cdot 8$ \\
\hline
\end{tabular}

$f f$, wind speed; $T_{\mathrm{w}}, T_{\mathrm{a}}$, and $T_{\mathrm{d}}$, sea-surface, air, and dewpoint temperature; $\Delta T$, sea-air temperature difference; $\mathrm{RH}$, relative humidity; $e$, water vapour partial pressure; SHF, LHF, and THF, sensible, latent, and total bulk heat flux.

Figure $2(20-30 \mathrm{~km}$ and $50-60 \mathrm{~km})$, smaller temperature differences are found. This variation is owed mainly to the variation of air temperature, while the sea-surface temperature varies only weakly, although similarly significant, around a mean value of $7^{\circ} \mathrm{C}$. The corresponding variation in dew point temperature does not, however, introduce a systematic variation in relative humidity. The sensible as well as latent bulk heat fluxes take on similar values for all diameter classes except for the largest, for which they both become definitely smaller. This is due to the previously mentioned variation of the sea-air temperature difference together with the slight reduction of wind speed with cell diameter.

Satellite images sometimes suggest, in correspondence with theoretical reasoning, that the cell diameter should increase with the distance from the coast. In order to test this it has been assumed that the observed surface wind direction has been the direction of the flow since it fell over water at a coast or ice boundary in a cold air outbreak. This assumption makes it possible to estimate the distance travelled by the air mass observed at Weathership M. No trend towards a larger cell diameter for larger distances to the coast line is found. This could mean that the above assumption of constant wind direction during a cold air outbreak does not generally hold. It also may reflect the possibility that only a few cases result from a consistent development starting at a coast or ice boundary. Instead most cases observed near Weathership M may have developed over the ocean as soon as the sea-air temperature difference was large enough for convection to start.

The relationship between convection height and cell diameter is given in Figure 8 . While small aspect ratios (5-20) are found with all convection heights the larger values (20-50) appear almost exclusively with convection heights of less than about $2500 \mathrm{~m}$. For comparison with other data for each cell diameter class the estimated standard error of the mean cloud top is plotted. This shows a general trend towards higher cloud tops for larger cell diameters. Although the corresponding correlation coefficients of 0.21 is very small, it is still significant at a 99 per cent level owing to the large number of data in the diagram. As this increase of convection height with cell diameter is small, convection height increases also with aspect ratio. This result has been reported earlier by Agee (1976) who analysed a few tens of cases containing only cell diameters below $50 \mathrm{~km}$. His data have been rearranged to the cell diameter classes of the present study and plotted into the present diagram. The estimated error of the mean in each diameter class is of the same order of magnitude as in our data. Miura (1986) found similar results for cell diameters smaller than $30 \mathrm{~km}$ in cold air outbreaks over the Chinese Sea. In his case a surprisingly small data scatter is reported, but the averages of all three data collections coincide remarkably. This general increase of the aspect ratio with cell diameter and convection height could hint at the importance of net latent heat release due to precipitation, which is rather small in cases of flat boundary layer clouds but increases with cloud depth. This would correspond to the findings of Chlond (1988). He argues that larger latent heat release may, on average, result in an increased static stability 


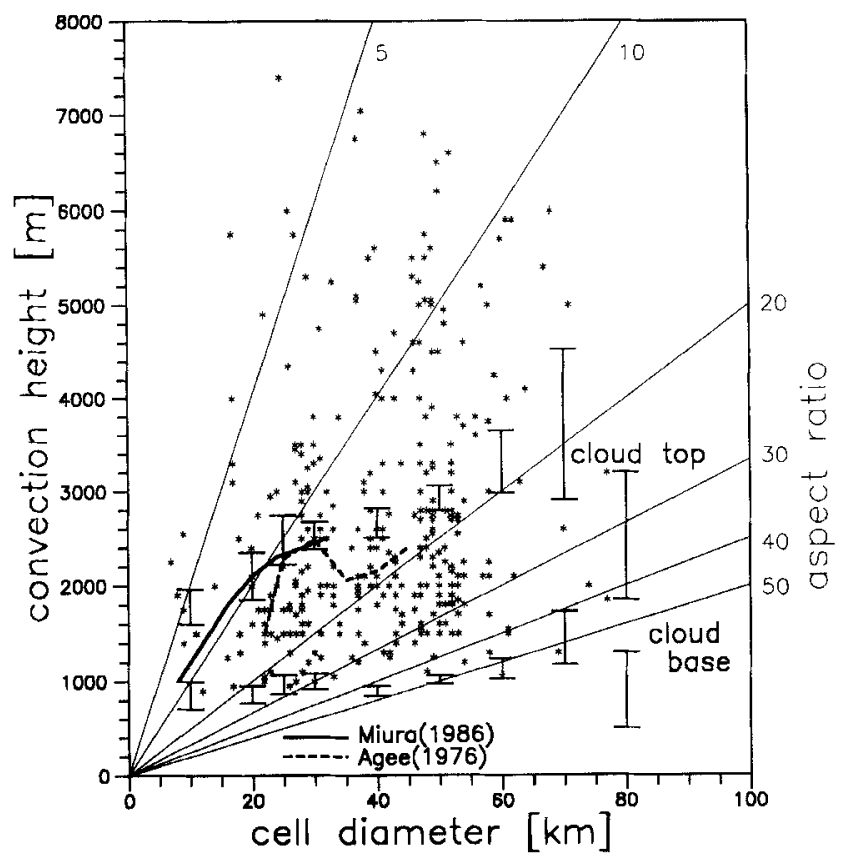

Figure 8. Convection height versus cell diameter for all cases of open cells near Weathership $\mathbf{M}$ and isolines of aspect ratio, The standard deviation of the mean convection height for each diameter class is indicated. For comparison, results from Miura (1986) and Agee (1976) are included. In addition, the average cloud-base level is indicated

of the (conditionally unstable) cloud layer above an absolutely unstable subcloud layer. Then the compensating subsidence around the updrafts should suppress more of the surrounding clouds the more stable the temperature profile is, leading to larger mutual distances and aspect ratios of the 'surviving' clouds.

Also the cloud-base height increases slightly with increasing cell diameter in Figure 8, but the correlation coefficient of 0.12 is only significant at the 95 per cent level.

\subsection{Convection layer stability}

The development of the convective boundary layer should be crucially determined by the layer stability. In the analysis of classical laboratory convection it is defined by the Rayleigh number. To characterize stability in a conditionally stable atmosphere the quantity

$$
\left(\frac{\partial T}{\partial z}-\frac{\partial T}{\partial z} /_{\mathfrak{m}}\right) /\left(\frac{\partial T}{\partial z}-\frac{\partial T}{\partial z} /_{d}\right)
$$

is used frequently as a stability parameter (e.g. Asai 1970; Van Delden, 1985; Chlond, 1988). The indices d and $\mathrm{m}$ characterize the dry and moist adiabatic temperature gradient. Using the gradient of saturated equivalent potential temperature $\Theta_{\mathrm{es}}$ this expression may be written as

$$
-\frac{\partial \Theta_{\mathrm{es}}}{\partial z} / \frac{\partial \Theta}{\partial z}
$$

In analogy to Miura's (1986) analysis the discrete version of this expression $S \approx-\Delta \Theta_{\mathrm{es}} / \Delta \Theta$ has been used to define a stability parameter, where $\Delta$ represents the difference between the convection height and the surface. It has to be mentioned that the value of $S$ depends strongly on the chosen convection height. 
For the present cases this stability parameter takes on values between +1 and -1 . Positive values are found mostly in cases of small convection heights, which correspond to rather small sea-air temperature differences. Convection heights above $3000 \mathrm{~m}$ exhibit mostly negative values of $S$.

Figure 9 shows the value of this stability parameter versus the aspect ratio. The positive values of $S$ for convection cases with small convection height exhibit a tendency to decrease with increasing aspect ratio. This is at least in qualitative agreement with Miura's (1986) observations and theoretical results. Also Chlond (1988) finds theoretical reasons for such a relation in flat convection where the Boussinesq approximation is still valid. His value of $10^{6}$ for a moist Rayleigh number represents the present cases best and seems to compare favourably with our data. Unfortunately, at these small convection heights we have no observations with very small aspect ratios, as these would correspond to horizontal cell dimensions below the resolution limits of the present study.

On the other hand, the bulk of data for convection heights above $3000 \mathrm{~m}$, which correspond to smaller aspect ratios, exhibit negative values of $S$. These have neither been considered by theoretical analysis till now, nor did Miura (1986) report such cases. The reason for these negative values lies in the vertical profile of $\Theta_{\mathrm{es}}$. The potential temperature $\Theta$ increases with height in almost any observed convection case (at least above cloud base), which makes $\Delta \Theta$ between cloud top and any height below a positive quantity. In contrast, near the surface $\Theta_{\mathrm{es}}$ usually decreases with height owing to the decreasing saturation specific humidity. However, above a particular height, the increase of $\Theta$ is larger than the decrease in the humidity component of $\Theta_{\mathrm{es}}$, resulting in an increase of $\Theta_{\mathrm{es}}$ with height. Therefore, the difference of $\Delta \Theta_{\mathrm{es}}$ between a low cloud-top height and the heights below is often negative, leading to a positive value of the stability parameter $S$. If, however, the cloud top is higher than about $3000 \mathrm{~m}$ the value of $\Theta_{\mathrm{es}}$ is usually larger than the near-surface value, resulting in the observed negative stability parameter value.

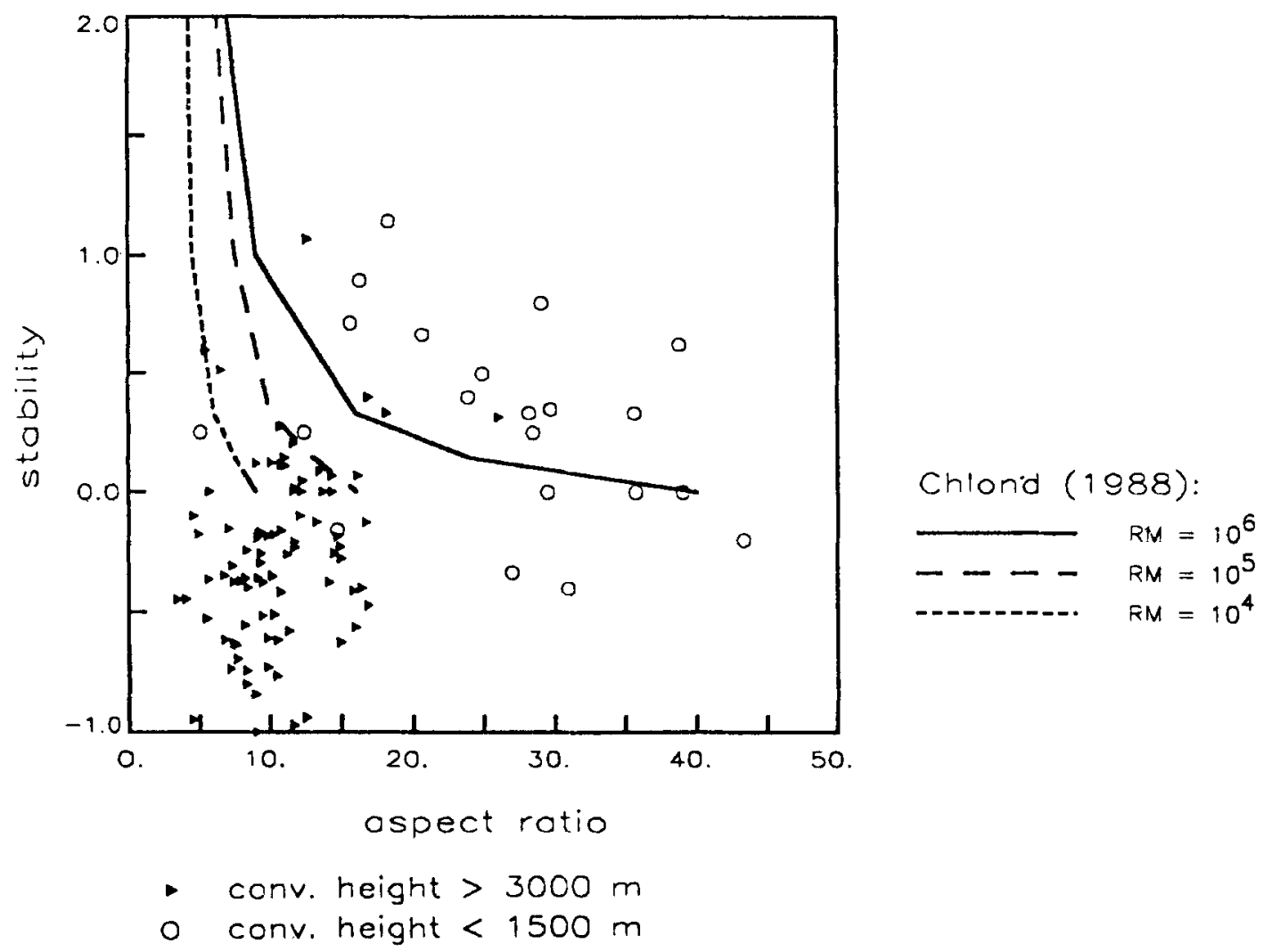

Figure 9. Stability parameter versus aspect ratio for two convection height regimes. Theoretical results of Chlond (1988) are added 
As a consequence, for simple theoretical modelling of cellular convection the usual assumption of a constant and positive stability parameter value throughout the convection layer is only valid for very flat boundary layers. Models representing convective boundary layers thicker than about $1000 \mathrm{~m}$ should, therefore, rather take into account a more realistic vertical variation of the stability parameter value.

\section{DERIVATION OF CELLULAR CHARACTERISTICS FROM SATELLITE DATA}

The results of section 3.2 hinted at a definite correlation between the surface heat flux and a (subjectively defined) degree of cellular organization. This apparent correlation will be elaborated in the present section.

\subsection{Characteristics of satellite data in cell cases}

Digital NOAA/AVHRR data of 62 scenes of open cellular convection around Weathership M were selected that cover the whole range of wind speeds and sea-air temperature differences for well- and less well-expressed cases. The channel 4 brightness temperature histogram of such a scene typically exhibits two maxima. One represents pixels that are either completely cloud free or (partly) filled by flat boundary layer clouds, whose channel 4 brightness temperature is very similar to that of the surface. Experience during the KonTur 1981 experiment (Brümmer et al., 1985) shows, for example, that the so-called open area of the cells frequently contains such low-level clouds. The second histogram maximum at lower brightness temperatures represents the tops of those clouds that constitute the ring structure around the open area. This second maximum is usually smaller than the first one and occasionally disappears completely. Therefore, the appearance of this second maximum allows us to split up our sample into three groups:

Type 1 - well-expressed secondary maximum at lower brightness temperatures, i.e. large area with high cloud tops ( 38 cases)

Type 2-Recognizable, but only relative secondary maximum at lower brightness temperatures (14 cases)

Type 3 - no secondary brightness temperature maximum recognizable, but still pixels at low brightness temperature (10 cases)

This succession of histogram types corresponds to a different amount of high-level cloudiness, which primarily may determine the degree of cellular organization. Obviously the existence of an expressed secondary maximum, i.e. of well-defined cloud rings, corresponds to the subjective impression of wellexpressed organization. Therefore, of the type 1 cases 27 belong to the originally estimated category "well expressed' and 11 to the category 'less well expressed'. In the case of type 3 only two scenes have been labelled 'well expressed', but eight scenes gave the impression of being 'less well expressed'. For type 2 an intermediate situation with eight cases 'well expressed' and six cases 'less well expressed' is found. Typical examples of these three groups may be seen in Figure 10.

For a more quantitative characterization of the frequency distributions the mean brightness temperature is used in the following. This quantity should be smaller the larger the frequency is of high-level cloud tops and the higher these cloud tops are. For practical intercomparisons, not the mean brightness temperature itself but its difference from the maximum brightness temperature in the scene is used, which should represent the surface temperature. The resulting MBTD (mean brightness temperature difference) should then be fairly independent of sea-surface temperature variations. The MBTD decreases from histogram type 1(14.5) to type $3(9.9)$. It represents mainly the fraction of pixels with high and cold cloud tops, which are defining the structure of the open cells. If the fractional coverage with cold cloud tops is derived from the second maximum of the histograms by defining a suitable threshold, this quantity is strongly correlated with the MBTD.

\subsection{Correlation between satellite and surface data}

As all the selected satellite scenes are centred near Weathership $M$, surface data are available for comparison. Despite a considerable data scatter Figure 11 shows that the sea-air temperature difference observed at Weathership M generally increases with increasing MBTD. The cases with observed histogram 


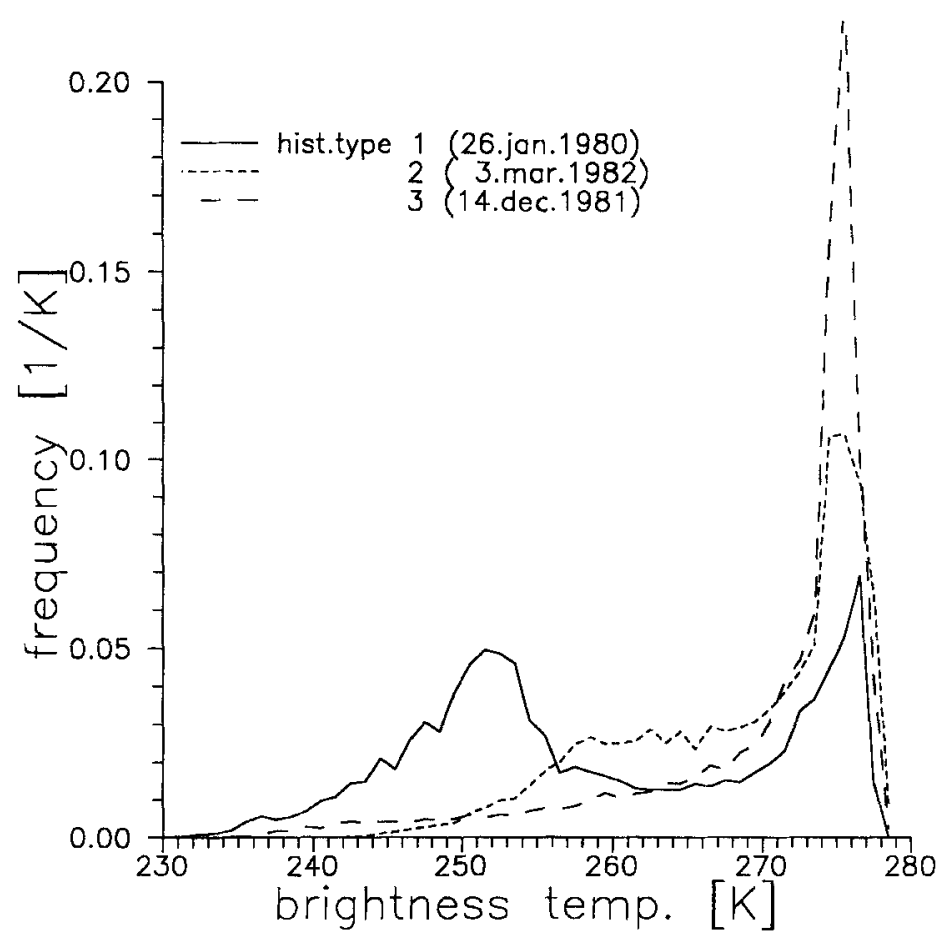

Figure 10. Channel 4 brightness temperature frequency distribution for three typical scenes

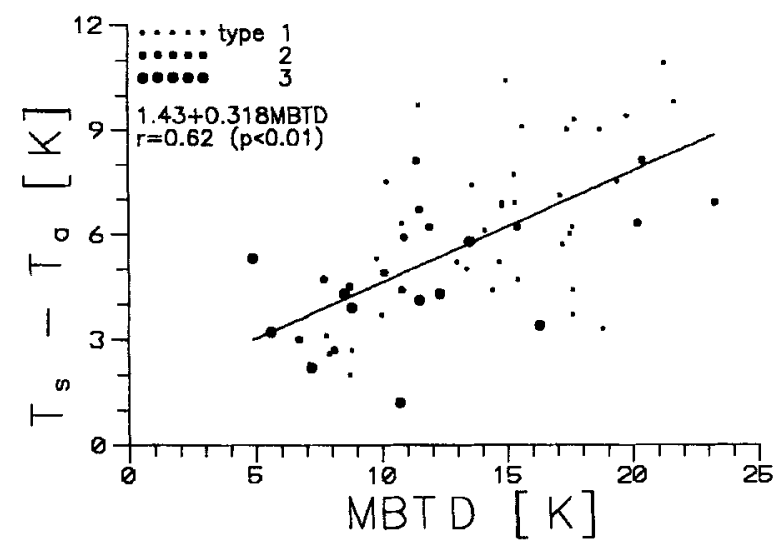

Figure 11. Sea-air temperature difference at Weathership $M$ versus mean brightness temperature difference from the maximum (sea surface) brightness temperature of the corresponding AVHRR channel 4 scene for the three histogram types. The linear regression is valid for all 62 cases

type 1 tend towards higher sea-air temperature difference and higher MBTD, while histogram type 3 cases appear at smaller values. Therefore, larger sea-air temperature differences result in a larger fraction of pixels with high cloud tops, which are defining the cell structure.

Figure 12 contains the sensible bulk surface heat flux versus the MBTD. Generally, the heat flux is higher the larger the MBTD is. Because of the scatter in wind speed the figure shows rather more scatter than is exhibited in Figure 11. This is even more apparent in Figure 13, where the (bulk) latent heat flux is correlated with the MBTD. Generally, all these correlations are higher for type 1 and 2 scenes than for type 3. 


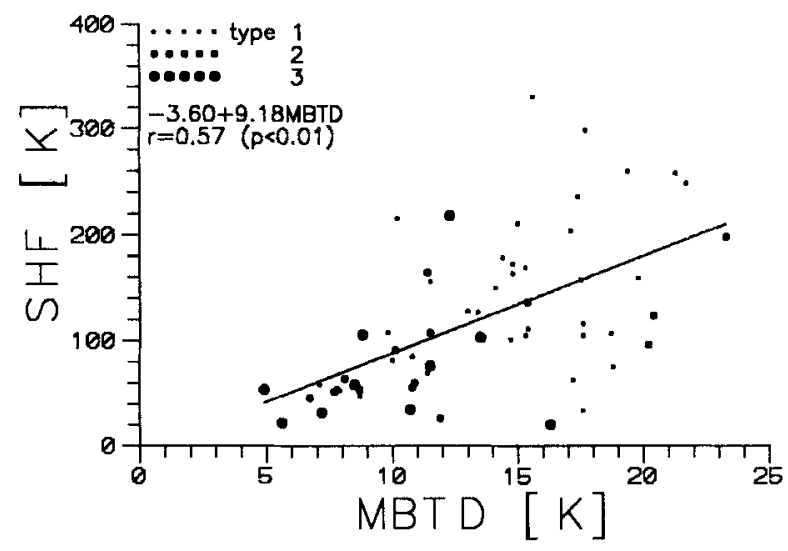

Figure 12. As in Figure 11, but for the bulk sensible heat flux

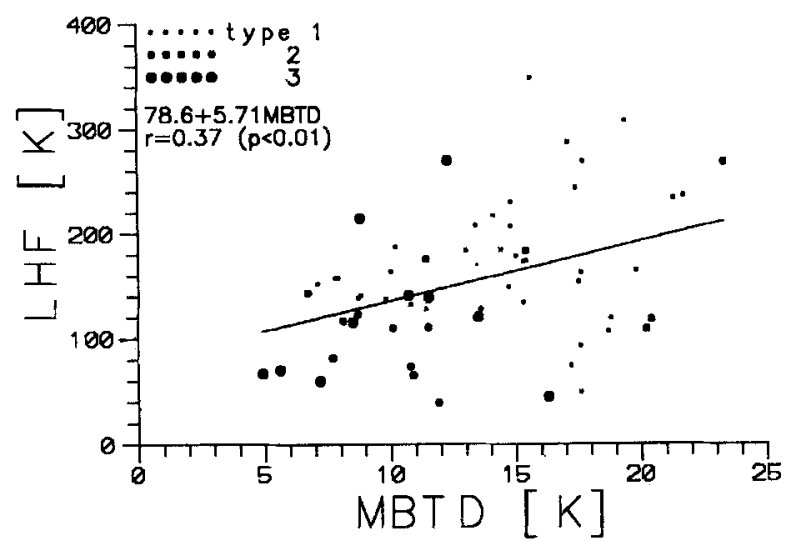

Figure 13. As in Figure 11, but for the bulk latent heat flux

Although all of the presented correlations exhibit a considerable data scatter, the correlation coefficients of all three figures differ significantly from $0(p<0.01)$. The correlation coefficient and its significance, however, are higher in the case of sea-air temperature difference than for the bulk heat fluxes. This fact seems surprising, as the development of a convective boundary layer should be determined primarily by the surface heat flux. However, it should not be the local heat flux that is the relevant quantity, but the heat flux $H(t)$ integrated along the trajectory of a cold air outbreak

$$
E=\int H(t) \mathrm{d} t
$$

The time necessary to reach Weathership $\mathrm{M}$ from some distance $L$ (e.g. the ice boundary) is of the order $L / v$, where $v$ is the wind speed. According to the usual bulk formulation the local sensible heat flux is proportional to $v \Delta T$, with the sea-air temperature difference $\Delta T$. As the sea-air specific humidity difference $\Delta q$ may be shown to be roughly proportional to $\Delta T$ too, the total heat flux across the sea-air interface also should be roughly proportional to $v \Delta T$. Assuming, for simplicity, that $v$ and $\Delta T$ do not change along the trajectory yields for the time integrated surface heat flux into the atmospheric column ( $C$ is some constant)

$$
E=\int H(t) \mathrm{d} t \approx C \times v \times \Delta T \times L / v=C \times L \Delta T
$$

According to this it seems plausible that the appearance of convection in a certain place is correlated with the sea-air temperature difference rather than with total heat flux, as is observed in the above diagrams. 


\subsection{Consequences for the remote sensing of surface parameters}

Finally, it could be asked whether the correlations discussed in the previous chapter may in turn be used to estimate surface heat fluxes and/or the sea-air temperature difference from AVHRR images. This is possible, as the channel 4 MBTD can be calculated easily for suitably selected satellite image scenes and the linear regression equations displayed in Figures 11-13 may be applied to estimate the respective quantities. The potential accuracy is then given by the sample scatter in the diagrams of the previous section, increased by a few per cent to account for the MBTD variance (Draper and Smith, 1980). As the RMS deviation from the linear regression line is $1.8 \mathrm{~K}$ for the sea-air temperature difference and about $60 \mathrm{~W} \mathrm{~m}^{-2}$ for both heat fluxes, a band of this width to both sides of the linear regression lines marks approximately the 67 per cent confidence limit of the prediction. Although these error figures appear fairly large, their value can be assessed only by comparison with values derived by other available satellite remote sensing techniques. Such a method exists only for the derivation of latent heat flux, using passive microwave signals of either the NIMBUS 7/SMMR or the DMSP/SMMI instruments. These are used to estimate the difference between specific humidity of the air and the saturation specific humidity for the estimated sea-surface temperature. Wind speed is either added from objective analysis data or estimated from microwave data.

Crewell et al. (1992) cite an RMS error of the order of $60 \mathrm{~W} \mathrm{~m}^{-2}$ for single scenes of $2^{\circ} \times 2^{\circ}$ size of NIMBUS 7/SMMR data, while for monthly mean values an RMS error of about half that size is typically reported (e.g. Liu, 1988). It has to be kept in mind that the microwave techniques are applicable in clear sky situations as well as with clouds in the field of view but not for pixels containing rain. As open cellular convection usually is associated with precipitation, these situations have to be mostly excluded from microwave flux studies. This results in a trend to neglect systematically the large fluxes in cold air outbreaks with the danger of biased mean flux values. Therefore, a complementary technique for these convective regions as proposed here, could make a considerable contribution to the derivation of correct average latent heat fluxes.

For the potential accuracies of the sea-air temperature difference or the sensible heat flux, no comparison values exist. In fact there are, to our knowledge, no proposals in the literature for the derivation of these quantities from remote satellite data at all.

\section{CONCLUSIONS}

The present study shows that the north-eastern Atlantic is frequently covered with open convection cells. Sometimes, but not always, these develop in a cold air outbreak from the ice-covered polar regions. In these cases, areas of wind-parallel cloud bands appear near the ice boundary as the initial development stage of the cold air mass over the relatively warm water.

From the observed number of open cell situations near Weathership $M$ and from the observed bulk surface heat fluxes it may be estimated that about 20 per cent of the yearly heat input from that part of the ocean to the atmosphere occurs during open cellular convection cases. This number makes the phenomenon a climatologically relevant one, at least in middle and northern latitudes.

Remarkable in this study seems the wide scatter of all derived data. Despite the occasional erroneous selection of cases this documents a wide variety of conditions related to the appearance of organized cellular convection. This is especially obvious in Figure 8 where the convection height for open cells of $40 \mathrm{~km}$ diameter varies between 1 and $7 \mathrm{~km}$. A similar data scatter is found in Agee (1976) after replotting his data to our format, but, surprisingly, Miura's (1986) data exhibit a considerably smaller scatter. Nevertheless, averages of all three studies coincide quite favourably, although this may be somewhat fortuitous.

The digital satellite data analyses exhibit the expected correlation between simple satellite observable quantities, such as the mean brightness temperature of a scene, and the surface heat flux or the sea-air temperature difference. The direct application of these correlations to estimate heat fluxes from the MBTD may be of limited value as cellular convective situations appear only sometimes over the ocean (e.g. in about 25 per cent of the time near Weathership M). Nevertheless, a rough estimate of both surface heat flux components in cases of large fluxes may be useful. In particular, the usual estimation of latent heat flux from passive microwave data may be complemented by this procedure. While microwaves usually are not overly 
influenced by cloud droplets, the same is not true for rain clouds. As a field of open convection cells contains rain showers the passive microwave data especially will be disturbed. If these conditions are encountered, the derived data have to be discarded, otherwise erroneous fluxes will be derived. In such cases our procedure might help to replace these data.

More generally, these results suggest that cloud structure information from satellite images may provide useful additional information in the estimation of surface properties over the ocean at least.

\section{ACKNOWLEDGEMENTS}

The authors are indebted to Professor Hinzpeter for closely guiding the work and to B. Zinecker for carefully typing the manuscript. The study was funded by the BMFT.

\section{REFERENCES}

Agee, E. M. 1976. 'Observational evidence of cell flatness as a function of convection depth and eddy anisotropy', J. Meteorol. Soc. Jpn, $54,68-71$.

Agee, E. M. 1984. 'Observations from space and thermal convection: a historical perspective', Bull. Am. Meteorol. Soc., 65, $938-949$.

Agee, E. M. 1987. 'Mesoscale cellular convection over the oceans', Dyn. Atmos. Oceans, 10, 317-341.

Agee, E. M. and Lomax, F. E. 1978. 'Structure of mixed layer and inversion layer associated with patterns of mesoscale convection during AMTEX 1975', J. Atmos. Sci., 35, 2281-2301.

Agee, E. M., Chen, T. S. and Dowell, K. E. 1973. 'A review of mesoscale cellular convection', Bull. Am. Meteorol. Soc., 54, $1004-1012$.

Asai, T. 1970. 'Three-dimensional features of thermal convection in a plane Couette flow', J. Meteorol. Soc. Jpn, 48, $18-29$.

Brümmer, B., Bakan, S. and Hinzpeter, H. 1985. 'KonTur: observations of cloud streets and open cellular structures', Dyn. Atmos. Oceans, 9, 281-296.

Brümmer, B. and Busack, B. 1990. 'Convective patterns within a field of stratocumulus', Mon. Wea. Rev., 118, 801-817.

Busack, B., Bakan, S. and Luthardt, H. 1985. 'Surface conditions during mesoscale cellular convection', Beitr. Phys. Atmos., 58, 4-10.

Chlond, A. 1988. 'Numerical and analytical studies of diabatic heating effect upon flatness of boundary layer rolls', Beitr. Phys. Atmos., 61, 312-329.

Crewell, S., Ruprecht E. and Simmer, C. 1992. 'Latent heat flux over the North Atlantic ocean-a case study', J. Appl. Meteorol., in press. Draper, N. and Smith, H. 1980. Applied Regression Analysis, Wiley, New York, 709 pp.

Hasse, L. and Dobson, F. 1986. Introductory Physics of the Atmosphere and Ocean, Reidel, Dordrecht, $126 \mathrm{pp}$.

Isemer, H.-J. and Hasse, L. 1987. The Bunker Climate Atlas of the North Atlantic Ocean, Vol. 2, Air-Sea Interactions, Springer, Berlin, $252 \mathrm{pp}$.

Krueger, A. F. and Fritz, S. 1961. 'Cellular convection patterns revealed by Tiros 1', Tellus, 13, 1-7.

Liu, W. T. 1988. 'Moisture and latent heat flux variabilities in the tropical Pacific derived from satellite data', J. Geophys. Res., 93, 6749-6760

Miura, Y. 1986. 'Aspect ratio of longitudinal rolls and convection cells observed during cold air outbreaks', J. Atmos. Sci., 43, $26-39$.

Sheu, P. J. and Agee, E. M. 1977. 'Kinematic analysis and air-sea heat flux associated with mesoscale cellular convection during AMTEX 1975, J. Atmos. Sci., 34, 793-801.

Smith, S. D. 1988. 'Coefficients for sea surface wind stress, heat flux, and wind profiles as a function of wind speed and temperature', J. Geophys. Res., 93, 15467-15472.

Taubenheim, J. 1969. Statistische Auswertung geophysikalischer und meteorologischer Daten, Akad. Verl. Ges., Leipzig, 386 pp.

Van Delden, A. 1985. On Cumulus Cloud Patterns and the Theory of Shallow Convection. University of Utrecht, $185 \mathrm{pp}$. 